\title{
Paul Schostakowsky.
}

\section{EUROPA Y RUSIA}

\section{E1 «Occidentalismo» y el «Rusismo», las dos co- rrientes principales de la cultura rusa}

(10)

ESDE muchos siglos el pueblo ruso, en la persona de sus representantes más cultos, de los pocos que al principio sabían leer y escribir, de su clero, y luego de sus profesores y sabios, está dividido en dos campos: el campo «Occidentalista» y el campo "Rusista». En el curso de los siglos ambos bandos, de acuerdo con los fines inmediatos que se proponían alcanzar, cambiaban sus nombres; los ideales de unos y de otros también evolucionaban, ganando o perdiendo en importancia, profundidad y extensión espiritual, pero en el fondo, los móviles principales que alentaban a unos y a otros, permanecían los mismos. El «Occidentalismo", sea que se llamara «letinis mo" (nombre que los antiguos rusos daban al catolicismo), sea que se llamara «influencia cultural»: alemana, francesa $o$, de manera más genérica, «europea», era la misma tendencia, que predicaba la introducción en Rusia de teorías, doctrinas y enseñanzas que profesaban, o de alcances materiales de que gozaban, los pueblos de la Europa occidental. Al contrario, el «Rusismo» era la tendencia que se oponía a la importación «occidental», sobre todo y principalmente a la importación espiritual, que consideraba todo lo soccidental», como perjudicial al pueblo ruso, en este y en el otro mundo, que acep- 
taba y quería fomentar solamente lo propio, lo ruso, que aseguraba que los rusos no necesitaban a los "occidentales", que podían vivir sirviéndose de la «razón propia» y en fin que era el Occidente el que tenía que aprender de los rusos lo que es la verdadera religión cristiana y la verdadera cultura espiritual.

El «Rusismo», que se generó para defender la verdadera piedad, abandono, en cierto momento, los límites puramente religiosos, para abrazar regiones espirituales y aun materiales de gran extensión, casi todo el conjunto de los intereses nacionales. Pero la corriente «nacionalista» se dividió rápidamente en varios arroyos, y últimamente la definición "un nacionalista», podía entenderse de la manera más variada. Una razón más para englobar todo el conjunto de las tendencias nacionalistas bajo el nombre genérico de "rusismo".

La discordia entre las dos corrientes resultará aún más clara precisando en seguida que, a mi parecer, el «occidentalismo» expresaba en todos los tiempos la tendencia rusa crítica, es decir, la tendencia de los que, descontentos de cómo las cosas iban en casa, buscaban en el Occidente los ejemplos y las enseñanzas, predicando la «europeización» de Rusia. Y el «rusismo» era la tendencia diametralmente opuesta: los «rusistas», muy satisfechos del estado en que se hallaba la patria, protestaban contra cualquier importación que chocara con la tradición nacional establecida.

La oposición de estos dos conceptos-del "occidentalismo", en el sentido de la cultura europea, y del "rusismo", en el sentido de la cultura rusa-plantea en primer lugar la pregunta: ¿Entonces Rusia no es Europa? Ciertamente no, y, tuera de los «occidentalistas» rusos, que se esfuerzan por enganchar a su patria a la cola europea, nadie duda de esto. Por lo menos la masa del pueblo y, ciertamente, una gran parte de los intelectuales rusos no se interesan en absoluto por ser considerados como un pueblo extramuros europeo.

Tolstoy decía que en los mapas geográficos, que representan Rusia, los cartógrafos no deberían escribir ni Europa ni Asia, sino Rusia. En cuanto a Dostoievski, era mucho más radical, y afirmaba que los rusos no son europeos sino asiáticos, y aun exhortaba a sus paisanos a reivindicar aquel título de "asiáticos» con orgullo, dejando la pretensión de llamarse «europeos».

Este punto de vista desesperaba a los "occidentalistas», sobre todo a los «occidentalistas» de las últimas generaciones, que crecían en épocas de depresión nacional, de la negación apasionada de todo lo que era lo propio, lo suyo, lo ruso, 
que querían y quieren asimilarse a la cultura europea, y esto no sólo en el sentido del estudio, sino como miembros de la misma familia y bajo el mismo rótulo. Y como ciertas diferencias entre los aspectos de la vida rusa y occidental no permiten, digamos, poner en la frente del mujik ruso el rótulo «europeo*, los detensores de aquella tendencia escriben tratados para comprobar que si el mujik ruso todavía no es un «europeo», en el sentido en que aquella palabra se entiende generalmente, es sólo por culpa del régimen zarista, que lo embruteció, y que bastaría anular «esto»e introducir «aquello» para que mañana mismo el mujik se convirtiera en un perfecto gentleman, y no hubiera ya diferencia alguna entre un ruso y un alemán o trancés o inglés de la misma condición social: ¡como si los alemanes, franceses e ingleses se parecieran entre sí!

El gran error de los «occidentalistas» consiste precisamente en olvidar o desconocer la historia de su propio pueblo y querer comprobar que Rusia vive, se desarrolla o retrocede según las mismas leyes que rigen en todas las colectividades occidentales, obedeciendo a la misma evolución social y movida por los mismos ideales. Esta afirmación me parece no menos exagerada que la suficiencia patriótica, que le oponen los «rusistas».

Antes de todo, el mismo Occidente no se presenta como un bloque cultural, regido por una ley única. Para convencerse basta tomar el ejemplo de la diversidad nacional en materia de las libertades políticas... Ahora, para explicar ciertas generalizaciones-a veces muy relativas-que unen a la mayoría de los países europeos, hay que tener en cuenta que todos estos pueblos tienen dos raíces comunes, que alimentaban a través de los sigios los gérmenes de sus culturas particulares: la primera eran los restos de la cultura romana y la segunda el catolicismo. $\mathrm{Y}$ aun cuando vino la Reforma, esta no se quedó como el privilegio de un solo estado, sino que se difundio por la mitad de Europa, y esto precisamente porque el catolicismo la unía. Consecuentemente, la Reforma quiso, como el catolicismo, ser universal.

Sin embargo, el caso de Rusia es otro. En vez de los restos de la cultura romana, los rusos encontraron en su llanura solamente los túmulos que marcaban el sitio de descanso de las tribus nómadas, que atravesaban aquel gran camino del sur de Rusia, que conducía de Asia a Europa. En cuanto a la religión, los rusos sacaron su fe de Bizancio (Constantinopla); es decir, en vez de unirse a los demás pueblos europeos bajo la tutela romana se encontraron opuestos a dichos pueblos 
a causa de la separación de las Iglesias católica romana y ortodoxa griega.

No hay duda que si entre los países occidentales existen diferencias de cultura-semejantes a la que se ofrecen entre los españoles y los ingleses, por ejempıo (diferencia cuantitativa), o entre los franceses y alemanes (diferencia cualitativa), y esto sin discutir la superioridad de una sobre otra-, ¿cuál tiene que ser entonces la diferencia-cuantitativa y cualitativa a la vez-entre los pueblos de la Europa occidental y Rusia? En consecuencia, es pura locura afirmar que el pueblo ruso pueda desarrollarse según las mismas leyes e ideales del Occidente, ya que a los rasgos específicamente raciales, religiosos y culturales, a la diferencia de los problemas políticos y nacionales, se añade un factor que pone a los rusos en una situación excepcional, no sólo en la familia de los pueblos romanos y anglosajones, sino entre los mismos pueblos eslavos: es su unión estrecha, unión de sangre y de intereses vitales con los pueblos asiáticos. No se trata en este caso de los intereses coloniales, semejantes a los que varios países europeos tienen en Asia, ni de simpatías o conveniencias políticas: se trata de una estrecha union tamiliar que dura tanto cuanto dura el estado ruso, y que ni los rusos ni los asiáticos pueden romper, aun si lo hubieran querido, ya que en aquella unión hasta los elementos de lucha, la cual se prolongó por espacio de varios siglos, fueron un cemento más en el fortalecimiento de relaciones familiares.

Diciendo «asiáticos» cometo tal vez un abuso: sería más correcto decir "mongoles», pero es siempre una inmensa parte del Asia, y si yo abuso de aquel sobrenombre, es para ser más explícito en cuanto a la contradicción irreconciliable en aue tenía y tiene que encontrarse el espíritu ruso con el espíritu europeo en más de un punto.

Tomando como techa de la conversión oficial del Occidente el año 325 , cuando el cristianismo fué proclamado religión oficial del Imperio romano, resulta que la conversión oficial de Rusia, que sucedió en el año 988 , se realizó seis y medio siglos después de la del Occidente. Y como en Rusia la Iglesia fué la primera fuente de la cultura, la primera escuela de los letrados, los «occidentalistas» afirman que el atraso cultural de los rusos sobre los europeos es de seis y medio siglos. De aquí la deducción: los rusos deben copiar lo que se hace en el Occidente, y mientras más fiel resulte la copia, menos habrá en ésta «invenciones» propias, lo cual sería mejor para Rusia. Lo que a estas afirmaciones contestan los «rusistas» ya lo 
sabemos. Pero lo interesante en la discusión no son las teorías, sino el ardor y la fe con que cada uno predica sus propias infalibilidades y perfecciones; para profesarlas los rusos no necesitan el apoyo de autoridad alguna: cualquiera es su propio juez y una autoridad infalible para sí mismo gracias a este método, que se aplica a la propaganda de cualquier teoría, y que es una tradición rusa secular, hay posibilidad de encontrar un inquietante parecido, digamos, entre los «viejos creyentes» del siglo XVII y los bolcheviques del siglo XX. Las teorías, los principios y los ideales se han hecho completamente opuestos, pero la pretensión de ser los únicos que siguen la vía justa-la única y verdadera - ha seguido siendo la misma. Los «viejos creyentes» se encerraban en sus iglesias y se quemaban vivos para no ver el triunfo del Anticristo, es decir de la Iglesia oficial; los bolcheviques, en vez de quemarse, inundaron el país con la sangre ajena; la diferencia es tremenda, monstruosa, pero, a través de las llamas, como en el fondo de aquel océano de lágrimas y de sangre, hay posibilidad de distinguir la misma insolencia de la idea fija, la misma porfía, la misma equivocación ingenua y grosera, que se cree infalible, y tres veces la misma ignorancia.

Puede ser que dividiendo de manera tan grosera en dos corrientes toda la evolución compleja de la cultura rusa vaya a provocar la indignación de muchos pedantes, pero lo que se pierde en la omisión de los detalles se gana en la claridad de la demostración, tanto más cuanto que la lección que yo quiero sacar de este ensayo-necesariamente incompleto por falta de espacio-se refiere a la continuidad de los métodos rusos, a la tradición y a la capacidad de asimilación específicamente rusos, y a los rasgos característicos de la cultura rusa, que le proporcionaron un puesto honorífico $y$ tan en vista entre los pueblos europeos.

Poniendo en el mismo saco «la verdadera religión o piedad», el "eslavofismo", el "nacionalismo" y el «rusismo», es lógico continuar y decir: el "bolchevismo" es también "rusismo», mientras que las tendencias de los partidos moderados, que actualmente se hallan en el destierro, es el "occidentalismo". Semejante afirmación levantará ciertamente vociferaciones en ambos campos rusos, así como entre los informadores «bolchevizantes» de la prensa occidental, pero no puedo retractarme, ya que esta manera de mirar las cosas permite explicar muchos sucesos confusos y nebulosos, proporcionando una nueva llave para el mejor entendimiento de lo que en el Occidente se llama a menudo «el enigma ruso». 
En la historia universal, después del Imperio Romano, no se halla otro ejemplo de la formación de un imperio semejante al Imperio ruso y que hubiera desempeñado en el mundo un papel de igual importancia. Pero, mucho más que su extensión territorial, parecen estupendos e incomprensibles los modos. de su formación y desarrollo. Si todo era lógico en el crecimiento sistemático de la potencia de Roma, y junto con esta de la cultura romana, todo fué ilógico en el crecimiento del estado ruso. En cuanto a la cultura rusa, su desarrollo presenta una paradoja que la historia nunca había repetido.

Para poder comprender los métodos y las vías de su formación, hay que dar un vistazo al pasado, y revisar, desde la primera época de la formación del estado ruso, lo que podían ser las dos corrientes que seguía la cultura rusa: la corriente "occidentalista», cuyos progresos dependían directamente de la intensidad de las relaciones con los países europeos y la corriente "rusista», la cual, tomando su primer impulso en la religión ortodoxa y, consecuentemente, en la influencia bizantina, se emancipó con rapidez y encontró en el alma de su propio pueblo elementos bastante fuertes para desarrollar sus propias tendencias espirituales $\mathrm{y}$, al mismo tiempo, para rusificar los préstamos occidentales, haciéndolos a veces desconocidos para los mismos prestamistas, que bajo los disfraces rusos no reconocían ni su espíritu ni su aspecto.

Los eslavos empezaron a arraigarse en el continente europeo en el siglo VII, pero la fundación del estado ruso hay que situarla en el año 862 , cuando los eslavos de la región noroeste de la Rusia actual llamaron a los príncipes varegos, "rus", para gobernar su tierra. En aquella época la masa de la población se hallaba concentrada en el valle del Dnieper, y sostenía relaciones comerciales muy animadas con los países escandinavos por un lado y con los puertos del mar Negro y Bizancio (Constantinopla) por otro. En los valles de los ríos que unían los mares del Norte con los mares del Sur y sus afluentes existían ciudades cuya importancia comercial y política fué notabilísima: Ládoga, Nóvgorod, Pólotzk, Smolénsk, Liúbech, Chernigov, Pereiaslav, Kiev, y que comerciaban no sólo con los escandinavos y bizantinos, sino también con el Oriente. Así, el escritor árabe Jordabé habla de los negociantes rusos que vió en 846 , es decir, diez y seis años antes de la fundación oficial del estado ruso, en Bagdad, adonde esos vinieron con sus mercancías. Los tesoros encontrados en el siglo pasado en varias ciudades rusas com- 
prueban que aquellas relaciones comerciales se establecieron en la primera mitad del siglo VII.

Entre las ciudades enumeradas, Nóvgorod y Kiev eran los puntos principales de la famosa ruta varego-griega, cuya existencia es conocicia ya de Heródoto; el Padre de la historia anota que el ámbar amarillo venía a Grecia desde el mar Báltico, precisamente por aquella ruta.

Los comerciantes eslavos necesitaban ciertamente protección para sus ciudades, protección para sus caravanas, y la idilia de la llamada de los príncipes varegos se explica por muchos historiógrafos como un prosaico alquiler de tropas mercenarias. Según esta versiọn, el primer duque «ruso», Rurik, vino a Nóvgorod como capitán mercenario, y aprovechó de su fuerza militar para imponerse a los ciudadanos que lo invitaron y proclamarse duque. Luego los varegos sometieron a su poder otras ciudades eslavas $y$, lo que es indudable, dieron al pueblo conquistado su propio, nombre: «rus», rusos.

Este período de la historia rusa presenta dos paradojas: la primera es la siguiente: los rusos se hallaban entonces arraigados en la parte más fértil de la Rusia europea, donde el suelo está formado por el famoso humus. En esta zona, que algunos siglos después y hasta la revolución, formaba por sí sola el granero de la Europa occidental, los rusos se ocupaban de industrias silvestres. Los objetos de su comercio de exportación eran, además de los esclavos, miel, cera, pieles, madera y, en cantidad insignificante, el trigo. Las ocupaciones principales de la población eran consecuentemente la apicultura, la caza y la industria silvestre; en cuanto a la agricultura, parecía ser cosa muy secundaria.

Otra paradoja: los príncipes varegos y sus tropas formaron en Rusia la clase superior de militares-comerciantes, que dominaba al pueblo y, normalmente, aquellos extranjeros, más cultos, mejor organizados, deberían imponer a sus súbditos medio salvajes sus costumbres, usanzas, idioma y religión; o, por lo menos, deberían conservarlos ellos mismos. Desde luego, ya en 945, Igor, príncipe varego de Kiev, como luego su heredero Sviatosláv, firmando con los griegos los pactos de paz, juraban por «nuestros dioses Perún y Volos», es decir, juraban por los dioses eslavos. El escritor árabe Al Becri (Siglo XI), cita las notas del judío Ibrahim, que conocía muy bien la Europa central y oriental y que a mediados del siglo $\mathrm{X}$ escribía que los varegos "rus», que dominaban ciertas tribus eslavas, se fundieron con éstas y adoptaron su idioma. Quiere decir que la capacidad de absorción, de la cual el pueblo ruso dió más 
tarde tantas pruebas estupendas, era una capacidad fundamental de la raza; los vencedores se diluyeron en la masa del pueblo sometido, y esto sin dejar otras huellas que algunas palabras normandas, muy contadas y también rusificadas.

De la unión del poder militar de los príncipes varegos con la organización estadista de las ciudades comerciales rusas salio una forma política que dió su nombre a todo un período de la historia rusa: el gran ducado de Riev

Kiev, más que las demás ciudades rusas de entonces, llamaba la atención de los varegos, por ser la llave de todo el sistema de la cuenca del Dnieper. Realmente, todos los afluentes del Dnieper se echan en este río por cima de Kiev. Su situación estratégica tenía también una importancia inmensa por el hecho de que Kiev estaba casi en la frontera de la región de los bosques vírgenes y de la estepa, y como los nómades, que pululaban en esta, eran el mayor peligro para las caravanas que bajaban o subían el Dnieper, camino a Bizancio, Kiev era el baluarte principal del comercio exterior ruso, la ciudad que concentraba el monopolio de los trámites con los nómades, que decretaba la guerra o la paz, que estaba, por decirlo así, en contacto directo y permanente con aquellos enemigos inasibles.

No hay nada de extraño entonces en que los primeros capitanes varegos que ocuparon Kiev, Askold y Dir, fueran asesinados por su compatriota Oleg, que llevaba ya el título de gran duque ruso, y que aun el futuro santo, el gran duque Vladimiro, que convirtió al pueblo ruso al cristianismo, maltratara a su hermano Iaropólk, arrebatándole Kiev.

Fn aquel tiempo la razón estadista, es decir, la razón de la existencia del estado ruso, consistía en el hallazgo de mercados extranjeros y en la defensa de las vías que conducían a éstos. Así las campañas de los rusos contra Bizancio tenía por motivo la no ejecución por los griegos de los tratados comerciales. Estas campañas-siempre victoriosas-eran bastante frecuentes, hasta que no cambiaron las condiciones de la existencia del estado ruso, hasta que no se presentaron otros fines políticos, que desviaron por completo el antiguo curso de la economía nacional. Askold en 860, Oleg en 907, Igor en 941 y 944, Sviatosláv en 971, triunfaron sobre los griegos y los obligaron a respetar los tratados, que regían las relaciones mutuas entre los negociantes rusos y bizantinos.

En aquellos tratados hay varios puntos interesantes para las características de ambos partidos contratantes. Llama la atención el hecho de que los griegos nunca se aventuraban 
a hacer el largo y peligroso viaje hasta Kiev, que eran los rusos los que venían a Constantinopla con sus caravanas náuticas, y que cambiaban sus mercancías contra el oro, la seda, el vino y las legumbres. Los griegos no sólo temían viajar a través de los países bárbaros, sino que temían a aquellos rusos en su propia capital, aun en calidad de huéspedes. Varios párrafos de los tratados están consagrados a los detalles de la entrada en la ciudad - por partidas de cincuenta hombres y sin armas-, así como a las reglas de estancia en Constantinopla. Los tratados preveían la comida gratuita de que gozaban los rusos, así como la gratuidad de los baños. Esta última pretensión es tanto más sorprendente de parte de los rusos salvajes, cuanto que en la Europa occidental, después de la ruina del Imperio romano, durante mil años, dice un historiógrafo, nadie había tomado un baño.

La preferencia que los rusos dieron a las dos direcciones principales de su comercio exterior-hacia Constantinopla y hacia Escandinavia-se explica perfectamente por las enormes ventajas que presentaban entonces las vías fluviales, comparativamente a las terrestres. Por las mismas ventajas se explica el desarrollo del comercio ruso con el Oriente en la dirección del sureste, con Persia y Arabia: era la vía fluvial del Volga y del Caspio la que facilitaba estas relaciones comerciales.

Por las mismas razones las relaciones directas con la Europa occidental eran sumamentes difíciles. Desde luego la curiosidad humana y el espíritu aventurero empujaban a los rusos a sostener ciertas relaciones de vecindad, a pesar de cualesquiera dificultades de orden material. Lo comprueba el matrimonio de Enrique I, rey de Francia, con la princesa Ana de Rusia, hija de Yaroslavo, gran duque de Kiev, matrimonio celebrado en 1051. Aquel Yaroslavo era el prototipo del rey Cristián de Dinamarca, suegro de tantos príncipes reinantes; efectivamente, la hija mayor de Yaroslavo-Elisabeth-estaba casada con Garold de Noruega, y su hija menor-Anastasiacon Andrés de Hungría. Con toda evidencia, Yaroslavo el sabio, como lo llaman los rusos, gozaba de gran prestigio entre los pueblos occidentales, prestigio que ciertamente podía ser mantenido sólo por relaciones seguidas con los países europeos.

Si los rusos las sostenían con los pueblos occidentales de otras razas, mucho más intensas han sido las relaciones con los eslavos occidentales, es decir, con los eslavos que vivían tras los Cárpatos y en la península balcánica. Las relaciones con los hermanos de raza revelaban ya preocupaciones de índole espi- 
ritual; lo comprueba el alfabeto eslavo. que vino a Rusia del Occidente.

Inventado por los apóstoles de los eslavos, los hermanos San Cirilo y San Metodio, fué adoptado, a excepción de los checos y de los polacos, por todos los pueblos eslavos. La Iglesia ortodoxa lo conserva todavía tal cual; en cuanto al alfabeto laico contemporáneo, es una transcripción, simplificada como dibujo, del antiguo alfabeto eslavo, que hace parecer las letras a las latinas, pero con diferencias esenciales de sonido y del número de las letras, que en el alfabeto ruso son treinta cinco. Esta riqueza de letras se explica por la introducción de letras especiales para los sonidos compuestos, así como de las vocales de distinta pronunciación. Cada uno de los sonidos $T c h, T z$, $S c h, C h, I a, I u, E$ dura, $E$ suave, etc., están representados en el albabeto ruso por una letra especial.

San Cirilo y San Metodio pertenecían a la lglesia occidental romana; los rusos aceptaron el alfabeto que ellos inventaron, pero no quisieron aceptar su fe; la fe la tomaron en Bizancio, pero $\sin$ alfabeto griego, traduciendo en seguida los libros santos a su idioma nacional. Decididamente, no existía para ellos ninguna autoridad absoluta y no sujeta a la crítica.

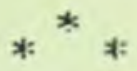

Las relaciones con el Occidente, y sobre todo las relaciones continuas y seguidas con Bizancio (Constantinopla), que desde la mitad del siglo IX tomaron el aspecto de relaciones estadistas regulares, tenían que inclinar a los rusos a abrazar el cristianismo. En 980 el trono del gran ducado de Kiev fué ocupado por Vladimiro, a quien la Iglesia ortodoxa canonizó más tarde. Hay que suponer que en aquella época el paganismo no satisfacía ya las exigencias espirituales del pueblo ruso; por to menos las crónicas antiguas guardaron el relato de las preocupaciones de Vladimiro para encontrar la mejor fe, ia más perfecta. Las crónicas nos conservaron también sus réplicas en el curso de las disputas religiosas, organizadas en $\mathrm{Kiev}$; nos transmitieron la forma algo enérgica con que él rechazó el judaísmo, y una palabra sublime, contestada al mufti musulmán, después de haber escuchado la exposición de los dogmas de la fe musulmana: impresionado por la prohibición de tomar el vino, San Vladimiro dijo: «No puedo aceptar tu religión: ¡beber es la alegría de los rusos! ఎ Las crónicas nos conservan también el relato de los delegados que Vladimiro mandó a Constantinopla para que viesen el culto cristiano. Impresionados por la 
solemnidad del oficio divino, que desarrollaba su fasto oriental en el cuadro suntuoso de la catedral de Santa Sofía, los enviados volvieron diciendo: «No sabíamos si estábamos en la tierra o en el cielo.»

De todo esto yo retengo solamente el hecho de que mientras que los otros pueblos fueron convertidos por los apóstoles y misioneros que venían a buscarlos, los rusos procedieron de manera opuesta: fueron ellos los que mandaron a buscar misioneros, y esto hay que retenerlo.

Vladimiro eligió finalmente la religión ortodoxa. Dejando completamente aparte la cuestión teológica, me parece interesante buscar, desde el punto de vista puramente histórico, las razones de aquella selección. Interesante en esto es lo siguiente: los hermanos San Cirilo y San Metodio eran los apóstoles de los eslavos. Este título les da la Iglesia ortodoxa, que los venera al igual de la Iglesia católica romana. La actividad civilizadora de los dos santos se desarrollaba entre los eslavos occidentales entre los años 855-885, es decir, con una anticipación de más de un siglo sobre la fecha de la conversión de los rusos.

Es muy probable que la luz del cristianismo hubiera llegado hasta Kiev antes, si los húngaros no hubieran cortado las relaciones entre los eslavos occidentales y los rusos. En 898 ellos atravesaron las estepas del sur de Rusia, y pasaron delante de Kiev, dirigiéndose al occidente. Al principio del siglo $\mathrm{X}$ se establecieron en el valle del Danubio. El reino de Moravia, que hoy día no es más que una provincia de Checoeslovaquia, se derrumbó bajo sus golpes. A su vez los bizantinos, en el siglo siguiente, arruinaron el primer reino búlgaro. Los eslavos del norte, arraigados en las orillas del mar Báltico, en la Pomerania actual, cedieron a su vez a la influencia alemana, y, junto con los checos y polacos, a la influencia católica. El mundo eslavo estaba destrozado.

Esto no había impedido a los letrados rusos, apenas convertidos al cristianismo, y mientras la situación general en el Occidente parecía contradecirlo formalmente, elevar su pensamiento hasta la idea de la unión paneslavista y aun buscar para la Iglesia recién nacida el apoyo de una sucesión apostólica directa. Para comprobar esta última el razonamiento era bastante ingenuo, pero significativo: San Metodio, apóstol de los eslavos, fué obispo de Panonia (así se llamaba en la antigüedad la región comprendida entre el Danubio y la Iliria, es decir, una parte de la Yugoeslavia de hoy día). El primer obispo de Panonia fué Andrónico, discípulo del apóstol Pablo, el cual 
a su vez vivió cierto tiempo en Iliria. De aquí se deduce que como Iliria y Panonia estaban pobladas por eslavos, y como los rusos son también eslavos, la sucesión apostólica directa de la cual gozan los rusos está comprobada.

Vistas la veneración que los rusos profesan para los dos primeros maestros eslavos, San Cirilo y Metodio, y la tendencia de los antiguos letrados rusos a establecer la sucesión apostólica directa, no por la vía de Bizancio (lo que hubiera sido natural y justo), sino por la vía occidental, ¿cómo fué posible que, llegado el momento de la conversión, los rusos buscaran las ordenes sagradas en la Iglesia oriental?

La contestación me parece ser esta: la separación de las iglesias, empezada en 858 , fué consumada definitivamente sólo en el año 1054, de manera que en el momento de la conversión rusa (988) la diferencia que hoy día existe entre las dos Iglesias no existía. Entre Constantinopla y Roma la discusión principal, aparte de algunos detalles insignificantes de ceremonias, giraba alrededor de la pretensión de los papas a la supremacía de la Iglesia romana.

En cuanto a los dogmas, la primera diferencia dogmática fué establecida solamente en 1014-15 por el papa Benedicto VIII, el cual introdujo en el credo-que antes era común en las dos Iglesias-la palabra filioque. El Papa Benedicto VIII lo hizo cediendo a las insistencias del emperador Enrique II. La lucha por la introducción de aquella palabra en el credo, sostenida por el clero español, tenía ya entonces una historia bi-secular; efectivamente, ya el papa León III (798-816), el que proclamó emperador a Carlomagno, tuvo que rechazar las insistencias análogas de éste, conservando el credo tal cual lo establecieron los concilios ecuménicos de Nicea y de Constantinopla. Esta tendencia de los emperadores a inmiscuirse en los asuntos de la Iglesia comprueba con qué verdadero interés, cálido y apasionado, los laicos se interesaban en aquellos tiempos por los asuntos religiosos: por una palabra del credo la gente era capa $z$ de subir a la hoguera, y ciertamente las autoridades eclesiásticas por sí solas nunca hubieran podido separar las dos Iglesias: para realizarlo se necesitaba no sólo el apoyo, sino el empuje de la opinión pública, y esto en ambos lados de la barrera.

Si la primera discordia dogmática fué sancionada veintiseis años después de la conversión de los rusos, los demás puntos que hoy día marcan la diferencia entre las dos Iglesias fueron introducidos en la Iglesia Romana mucho más tarde: en la época de la conversión rusa el clero secular católico se casaba como 
el de los griegos, los laicos católicos comulgaban al igual del clero con «sangre y cuerpo" (fueron privados del cáliz solamente en el siglo XII); en fin, el principal obstáculo para una nueva unión de las dos Iglesias-el dogma de la infabilidad del papadata solamente de 1870 .

Resulta que en el momento de la elección del culto, para el gran duque Vladimiro debía ser igual someterse a la autoridad eclesiástica griega o a la autoridad eclesiástica romana. Insisto en precisarlo, para subrayar la deducción: la decisión fué dictada, antes de todo, por consideraciones políticas. Cierto, las relaciones comerciales continuas con Constantinopla tenían que originar una cierta predisposición en favor de la Iglesia oriental, predisposición de costumbres y de relaciones personales, y la simpatía por el culto bizantino que fomentaban los cristianos secretos, que se encontraban entre los rusos mucho antes de la conversión oficial. Desde luego la seriedad con la cual San Vladimiro se consagró al estudio del problema religioso ponía al mismo nivel la autoridad de los legados del Papa y la de los enviados del patriarca griego. Consecuentemente hay que suponer-y para esto existen indicaciones indudables-que Vladimiro quiso poner la nueva Iglesia rusa en dependencia jerárquica de la autoridad clerical, que políticamente era más débil. Es curioso notar, para afirmar esta suposición, que Vladimiro, que podía perfectamente pedir a la autoridad eclesiástica griega que le enviara una delegación de clérigos para bautizar al pueblo ruso y servir de primeros cuadros eclesiásticos rusos, no quiso proceder en forma diplomática, y, en vez de pedir, conquistó su nueva religión manu militari, emprendiendo en 988 una campaña contra el Kersonés de Tauride, que era entonces una colonia bizantina, e imponiendo a los griegos, por un tratado de paz, la obligación de mandar una misión religiosa para efectuar la conversión de su pueblo. Claro que si San Vladimiro era a tal punto celoso de su independencia, la Iglesia Romana tenía que parecerle mucho menos interesante que la griega, por tener una mano secular poderosamente armada, en la persona del Santo Imperio de entonces.

Pero aquella manera de conquistar su fe tenía que reflejarse sobre la composición del clero que los griegos mandaron al lejano Kiev. Los primeros misioneros que llegaron se consideraban más bien en destierro que en una misión honorífica, y esto puso en seguida un límite al desarrollo de la influencia bizantina. Desde los primeros años de la conversión se despertó en el pueblo ruso el deseo de obtener para su propia Iglesia la independencia de cualquier autoridad eclesiástica extran- 
jera. (Sueño que se realizó solamente en 1789.) Cierto que el mayor empuje para el crecimiento de aquella tendencia fué dado por el clero griego, cuya reputación ha sido rápidamente establecida: una crónica del siglo XII, hablando de un obispo, dice: "y era adulador, ya que era griego".

El cristianismo fué asimilado por el pueblo ruso con una rapidez asombrosa, que puede explicarse solamente por las predisposiciones místicas del pueblo: cien años después de la conversión ya existía en Kiev el famoso monasterio de Pechersk y entre los monjes que salvaban allí sus almas se citaban asombrosos ejemplos de ascetismo y de virtudes cristianas.

En cuanto a la influencia cívica de los bizantinos, su mayor huella la encontramos en un notable monumento de jurisprudencia: "LA VERDAD RUSA". Bajo este nombre se conoce la primera codificación, que era más bien un manual de la práctica judicial que un código de leyes, compilada de acuerdo con los manuales griegos y más especialmente con las famosas Institutas de Justiniano I, Emperador de Oriente de 527 a 565. Lo más notable en «LA VERDAD RUSA» es que los originales griegos sirvieron a sus autores solamente de índice de materiales, del cual el legislador ruso se servía como de memoria, para no olvidar esto o aquello, mientras que el espíritu del código, en cuanto a la administración de los castigos es ruso; fué copiada solamente la clasificación de las acciones criminales, mientras que de los castigos bizantinos quedaron sólo las multas. El cristianîsmo al llegar a un país bárbaro y pagano fué aceptado por los corazones rudimentarios con tanta fe y sinceridad, que aquel código ruso, editado en la primera mitad del siglo XI por el gran duque Yaroslavo, hijo de Vladimiro, desconocía en absoluto la pena de muerte y aun los palos y las varas: el castigo consistía generalmente en una multa, que varía según la gravedad del caso. El bandolerismo, que se consideraba como el mayor crimen-claro está, por perjudicar la razón de ser del estado ruso de entonces, que era comerciar con el extranjero-, se castigaba con la confiscación de los bienes y la venta en esclavitud del culpable con toda su familia. Compilada de este modo, «LA VERDAD RUSA " parecía no ser más que una lista de tarifas: pagando, uno podía hacer lo que quería, de manera que la Iglesia, que vigilaba el orden no sólo religioso, sino moral $y$ el de la vida familiar, tuvo que intervenir, y, para no dejar ciertos crímenes, como por ejemplo. el asesinato de un siervo, completamente impunes, imponía a los culpables una penitencia.

Pero sería absolutamente erróneo creer que este sistema de 
multas fué promulgado para servir los intereses financieros del estado; repito que no era más que la aplicación práctica de los grandes principios del cristianismo. Que esto fué realmente así, lo comprueba el testamento de Vladimiro Monomáj (11131126), que era nieto de Yaroslavo y, por consiguiente, biznieto de San Vladimiro, y que decía: "no matad ni al justo ni al culpable». Quiere decir que por lo menos cuatro generaciones se educaban en el cumplimiento del mandamiento: ino matarás! Pido al lector que precise solamente: ¿cuál era la justicia de entonces en los países cultos de la Europa occidental?

El método que los antiguos juristas rusos emplearon al compilar "LA VERDAD RUSA» es uno de los ejemplos más notables del método cultural ruso; más adelante vamos a ver a cada paso la presencia de aquel espíritu crítico, que ya se reveló en la selección de la religión, y que, consciente de su propia fuerza, acepta cualquier cosa en la medida en que le parece conveniente, "rusificándola» en seguida, sea que fuese una palabra o una ley, una invención o una industria. De este modo comprueba la presencia de aquella tendencia de originalidad $y$ de genio propio, que ha permitido finalmente a Rusia ocupar un puesto prominente en la política y las artes europeas.

$$
*^{*} *
$$

La importancia de Kiev durante aquel período de la historia rusa se revela por las leyendas que nos conserva el folklore nacional. El brillo de la corte de Kiev se encuentra confirmado, además de por las canciones y baladas, por las crónicas antiguas. Bajo Yaropolko (980), Kiev festejaba la venida de los embajadores griegos; bajo San Vladimiro en Kiev se realizaron solemnidades sin par: el bautismo en el Dnieper de toda la población kieviana, el derrumbe solemne de los antiguos dioses, los bautismos de los príncipes extranjeros- «pechenegos» y búlgaros-, recepciones de los delegados del Papa, de embajadas de Grecia, Polonia, Checoeslovaquia, Hungría, etc. Las fiestas que San Vladimiro daba eran notables por su lujo y refinamiento: así, por ejemplo, durante las comidas de gala tocaba la música. Kiev era, además, el centro de la piedad rusa con su famoso monasterio Kievo-Pechérsk, que sobrevivió a los «polovtzi» y a los tártaros, y que fué arruinado, novecientos treinta años después de su creación, por los bolcheviques. Una crónica antigua afirma que durante un incendio de la ciudad, provocado por un ataque inesperado de los "polovtzis, perecieron en le fuego 700 iglesias. 
Son muchos los testimonios que no permiten dudar de la importancia que tenía el Kiev de los siglos X a XIII.

Desde luego, por razón de la lentitud del proceso de la formación de un pueblo, de una nacion, ningún documento escrito (ruso) de aquella época menciona el pueblo ruso: todos hablan de la tierra rusa. La idea nacional empieza a elevarse por encima de la concepción territorial solamente a fines del siglo XII. El despertar de la idea nacionalista precisamente en aquel momento es una nueva paradoja histórica, puesto que, consiguientemente a la división de la herencia dejada por San Vladimiro, el territorio se dividió en un sinnúmero de pequeños ducados que rivalizaban entre sí. Varios historiógrafos llaman a este nuevo período que empezaba el período feudal. Pero en realidad el sistema feudal, tal cual fué establecido en el Occidente, era completamente ignorado en Rusia. La repartición del territorio entre los herederos y los herederos de los herederos del primer duque ruso Rurik, se parecía a la division del patrimonio entre los hijos de cualquier burgués, y estaba lejos de cualquier idea estadista. Cada uno de aquellos potentados consideraba la tierra que le era adjudicada como su finca particular. De aquí las peleas continuas entre los duques, peleas en las cuales el pueblo sufría - como se puede imaginarmaterial y moralmente. Pero la conciencia nacional estaba ya despierta: el pueblo consideraba el conjunto de los ducados independientes como una sola «tierra rusa»y a las poblaciones que la cubrían como un solo "pueblo ruso".

Aquellas luchas interiores debilitaban a la nación hasta el punto de que pronto el empuje de los nómades, que atacaban el gran ducado de Kiev, el más expuesto, del lado de la estepa, creó en éste condiciones de vida excesivamente penosas. La dificultad de la lucha con los nómades consistía en la imposibilidad de asirlos. Los «polovtzi» no tenían ni ciudades ni bases, y si los rusos emprendían una campaña para castigarlos, encontraban delante de sí la estepa desierta, pero, apenas daban media vuelta para volver a casa, el enemigo aparecía persiguiéndoles, sin tregua. Finalmente la población se cansó de vivir en alerta continua y empezó a emigrar en dirección del nordeste, en la región comprendida entre el curso superior del Volga y el río Oka.

Pero antes de que ese movimiento de disolución se acentuara, en la vida europea empezó una época memorable: la Europa cristiana se alzó contra el mundo musulmán; empezàron las cruzadas, que duraron, con intervalos, de 1096 a 1291. Aunque el entusiasmo guerrero de los pueblos del Occidente fué susci- 
tado por la idea de quitar a los infieles la posesión de los Santos Lugares, en el fondo, ellas eran un acto de defensa contra las invasiones de los pueblos asiáticos, que en tres direcciones querían abrirse paso hacia Europa: el flanco izquierdo, partiendo del norte del Africa atacaba el Occidente a través de España; el centro se esforzaba en invadir Europa partiendo del Asia menor, vía Constantinopla y los Balcanes, mientras que el flanco derecho atacaba a Rusia. En esta última región la lucha ha durado varios siglos; finalmente los rusos han podido mantener sus posiciones, pero ¿a qué precio?

Desde luego no hay mal que por bien no venga: fué precisamente aquel sentimiento de peligro común el que despertó por primera vez la idea de la unidad nacional, que añadió a la nación del "territorio ruso" la de la «nación rusa». Pero mientras la población del gran ducado de Kiev, bajo los golpes repetidos de los nómades se desbandaba, la ruta de Constantinopla se hacía cada año más insegura y las relaciones comerciales se aminoraban. El golpe de gracia a aquel tráfico fué dado por los jefes de la cuarta cruzada (1202-1204), los cuales, bajo el pretexto de socorrer a dos príncipes bizantinos, destronados por su hermano Alejo III, ocuparon Gonstantinopla, robaron y destruyeron una infinidad de maravillas artísticas, arruinaton la población, y luego establecieron en la antigua capital bizantina un imperio latino, que existió cincuenta y siete años.

Desde luego los dos siglos de lucha continua con los «polovtzi» , la despoblación consiguiente de la comarca de Kiev, la toma de Constantinopla por los cruzados y la ruina del comercio exterior ruso, eran bagatelas comparadas al golpe que esperaba a Rusia en la primera mitad del siglo XIII. El famoso GhengisKan, que creó el inmenso imperio mongólico, mandó sus hordas contra los rusos. En la batalla en las riberas del Kalka, en 1224, las tropas rusas, bajo el mando de varios duques, que intrigaban y peleaban unos contra otros, fueron exterminadas por los tártaros. Los vencedores festejaron su victoria con una orgía, celebrada en planchas puestas sobre los pechos de los príncipes rusos, atados y colocados en el suelo. Desde luego, los tártaros aprovecharon muy poco su victoria $\mathrm{y}$, después de robar e incendiar las ciudades más cercanas, desaparecieron nuevamente en la estepa. Sólo en 1237, Batiy, uno de los nietos de Ghengis-Kan, invadió Rusia. Desgraciadamente la batalla de Kalka resultó de poca enseñanza para los príncipes rusos, y Batiy los encontró desunidos como lo estaban trece años antes. Rusia cayó bajo el yugo tártaro. Desde luego Kiev fué tomado 
por los tártaros solamente en 1240. Esta vez la ciudad recibió un golpe del cual no se levantó más. Se necesitaron siglos para devolverle una parte de su importancia anterior.

De este modo pereció el baluarte de la cultura rusa, "la madre de las ciudades rusas», como llama el pueblo ruso a Kiev, atestiguándole así su cariño y su agradecimiento por la luz cristiana y cultural, que fué encendida allí para iluminar la vida rusa y que brillaba tanto tiempo en los altos montículos, al borde del Dnieper, adonde se erige aquella ciudad maravillosa.

La ruina de Kiev y la dispersión de los restos de la población de su comarca, obligaron al pueblo a buscar otro punto de agrupación política. Digo pueblo y no digo nación, porque ésta existía sólo en el sentimiento de la población de un país mal definido y confuso como límites de territorio y con la vida política completamente desorganizada. El nuevo centro fué hallado mucho más al nordeste, en la región de Rostov Suzdal, Vladimir. Allí el pueblo se encontró completamente aislado del Occidente. La inseguridad de la estepa en el sur cortó las relaciones comerciales con los Balcanes; nuevos enemigos aparecieron del lado del Occidente y al noroeste, y las relaciones con los países europeos fueron rotas casi por completo. Empezó una nueva época en la historia rusa, que nuevamente parece ser una paradoja: si los rusos del gran ducado de Kiev, arraigados en el suelo maravillosamente fértil conocido bajo el nombre de "chernozém»- tierra negra", ya que ésta, por ser humus, es negra como el carbón-; si, digo, los rusos despreciaban entonces, como lo hemos visto, la agricultura, ahora, en posesión de un suelo arcilloso infinitamente más pobre, se entregaron al cultivo de la tierra, ocupación que era tanto más ingrata puesto que esa tierra poco fértil había que arrebatarla al bosque. Para sembrar era necesario cortar los árboles, quemarlos, desarraigar los troncos y, sólo después de tanto trabajo, había posibilidad de labrar la tierra, abonada con las cenizas. Un cambio tan radical en la economía nacional no era más que la consecuencia de la pérdida de los mercados extranjeros, de la ruina del comercio exterior y de la necesidad de encontrar en el país mismo los medios de existencia. La cultura rusa también entró en un período nuevo, ya que una de las dos corrientes culturales que la alimentaban--la corriente *occidental»-se secó, por haber sido cortadas sus fuentes. Sólo Nóvgorod y Pskov continuaban, al noroeste sosteniendo ciertas relaciones con el Occidente, mientras que la masa del pueblo ruso quedaba bajo la influencia unilateral de la corriente 
"rusista», que tenía que resolver un problema capital para la existencia del estado ruso: crear, con los pocos elementos que le quedaban, un centro político $y$, alrededor de este, agrupar a la nación.

Mientras tanto la llama de la cultura, encendida en Kiev, y a la luz de la cual brillaban las tendencias humanitarias de los primeros duques rusos, había sido apagada.

En mi artículo siguiente voy a exponer cómo un día esa llama se encendió nuevamente al borde del río Moscova. Desgraciadamente los nuevos cuidadores de la llama divina, despertando la cultura rusa después de su largo letargo, no recordaban el espíritu humanitario que cultivaron los primeros príncipes rusos, no recordaban las disposiciones legales que al principio del siglo XI permitían poner a Rusia a la cabeza de las naciones cristianas por el espíritu evangélico que profesaban sus gobernantes. (1).

(1) Discutiendo el problema de las dos corrientes de la cultura rusa, los polemistas toman ordinariamente como punto de partida el siglo $\mathrm{XV}$, cuando el desarrollo del estado y de la vida social permite hallar las primeras huellas de la lucha entre las dos tendencias. He seguido en este caso otra vía para que los lectores, poco familiarizados con la historia rusa, y sobre todo con la historia de la Iglesia ortodoxa, no tomasen a Moscú por cuna de la cultura rusa. Esta nació en Nóvgorod (hecho que por falta de espacio no he podido mencionar), y luego tomó aspecto cristiano en Kiev. Despertándose más tarde en Moscú, la cultura rusa, si no tenía tras sí una hoja de servicios muy extensa, por lo menos poseía un hilo de ligazón con su pasado: la Iglesia. 